\title{
Drug Safety in Translational Paediatric Research: Practical Points to Consider for Paediatric Safety Profiling and Protocol Development: A Scoping Review
}

\author{
Beate Aurich ${ }^{1}$ and Evelyne Jacqz-Aigrain $1,2, *$ (D) \\ 1 Department of Pharmacology, Saint-Louis Hospital, 75010 Paris, France; beate.aurich@gmx.fr \\ 2 Paris University, 75010 Paris, France \\ * Correspondence: evelyne.jacqz-aigrain@aphp.fr
}

check for

updates

Citation: Aurich, B.; Jacqz-Aigrain, E. Drug Safety in Translational Paediatric Research: Practical Points to Consider for Paediatric Safety Profiling and Protocol Development: A Scoping Review. Pharmaceutics 2021, 13, 695. https://doi.org/ 10.3390/pharmaceutics13050695

Academic Editors: Nunzio Denora and Rosa Maria Iacobazzi

Received: 8 April 2021

Accepted: 7 May 2021

Published: 11 May 2021

Publisher's Note: MDPI stays neutral with regard to jurisdictional claims in published maps and institutional affiliations.

Copyright: (c) 2021 by the authors. Licensee MDPI, Basel, Switzerland. This article is an open access article distributed under the terms and conditions of the Creative Commons Attribution (CC BY) license (https:// creativecommons.org/licenses/by/ $4.0 /)$.

\begin{abstract}
Translational paediatric drug development includes the exchange between basic, clinical and population-based research to improve the health of children. This includes the assessment of treatment related risks and their management. The objectives of this scoping review were to search and summarise the literature for practical guidance on how to establish a paediatric safety specification and its integration into a paediatric protocol. PubMed, Embase, Web of Science, and websites of regulatory authorities and learned societies were searched (up to 31 December 2020). Retrieved citations were screened and full texts reviewed where applicable. A total of 3480 publications were retrieved. No article was identified providing practical guidance. An introduction to the practical aspects of paediatric safety profiling and protocol development is provided by combining health authority and learned society guidelines with the specifics of paediatric research. The paediatric safety specification informs paediatric protocol development by, for example, highlighting the need for a pharmacokinetic study prior to a paediatric trial. It also informs safety related protocol sections such as exclusion criteria, safety monitoring and risk management. In conclusion, safety related protocol sections require an understanding of the paediatric safety specification. Safety data from carefully planned paediatric research provide valuable information for children, parents and healthcare providers.
\end{abstract}

Keywords: paediatric; clinical trial as topic; translational medical research; pharmacovigilance; clinical trial protocol as topic

\section{Introduction}

Paediatric translational research facilitates an integrated, multidisciplinary and multidirectional approach aiming to improve children's health [1-3]. Clinical trials are an important component of such research [3]. The planning of paediatric trials is informed by nonclinical and clinical data [4]. However, missing information on paediatric pharmacokinetics (PK), pharmacodynamics (PD), and safety should be proactively addressed in the study protocol [4-7]. This may include the use of innovative trial designs [8,9].

An integral part of paediatric trials is the assessment of treatment related risks and their management $[4,5,10-12]$. The collection and analysis of safety data as well as pharmacovigilance and risk management of paediatric trials are guided by the current understanding of the paediatric safety specification of the study drug or intervention $[4,6,7,11,13]$. Safety data evolves continuously. It may originate from a variety of data sources (e.g., in vitro studies, modelling and simulation, clinical trials, spontaneous reports, pharmacoepidemiology) [6,7]. The paediatric safety specification uses all available data to describe identified and potential treatment related risks and missing safety information $[4,6,7]$.

Treatment response in children differs from adults and between different paediatric age groups [14-17]. Therefore, it is important to ensure that drug safety related protocol sections are based on current, age group specific safety specifications $[4,5,7]$. This informs, 
for example, case report form (CRF) design, informed consent/assent, risk management, pharmacovigilance, and planning of the resources needed for safety data analyses (e.g., programming) $[4,5,18]$. Whilst there is consensus that safety data for children is often lacking, the practical aspects of paediatric drug safety in the context of clinical research should be considered [19].

Thus, the objectives of this scoping review of the literature were to identify and summarise practical points to consider on how to establish a paediatric safety specification and how this information is subsequently built into a paediatric protocol.

\section{Methods}

PubMed, Embase, Web of Science and websites of regulatory authorities (EMA, FDA) and learned societies (CIOMS and WHO) were searched for publications, in English up to 31 December 2020, describing how a paediatric safety specification is developed and how it informs paediatric protocol development (Appendix A Table A1).

Titles and abstracts were screened and full-text articles were reviewed where applicable. In a second step, information from health authorities and learned societies relating to pharmacovigilance, risk management and protocol development was analysed.

\section{Results}

A total of 3534 publications were identified. After removing 54 duplicates, 3480 publications were screened (Appendix A Figure A1). No publication was identified providing practical advice on how to develop a paediatric safety specification and how this informs a paediatric protocol. Relevant information was found in a variety of, mostly regulatory, guidance documents. Therefore, information from health authorities, learned societies and the specifics of paediatric research were merged. The methodology for developing a paediatric safety specification and how it fits into the larger picture of paediatric drug safety research and risk management was summarised (Figure 1).

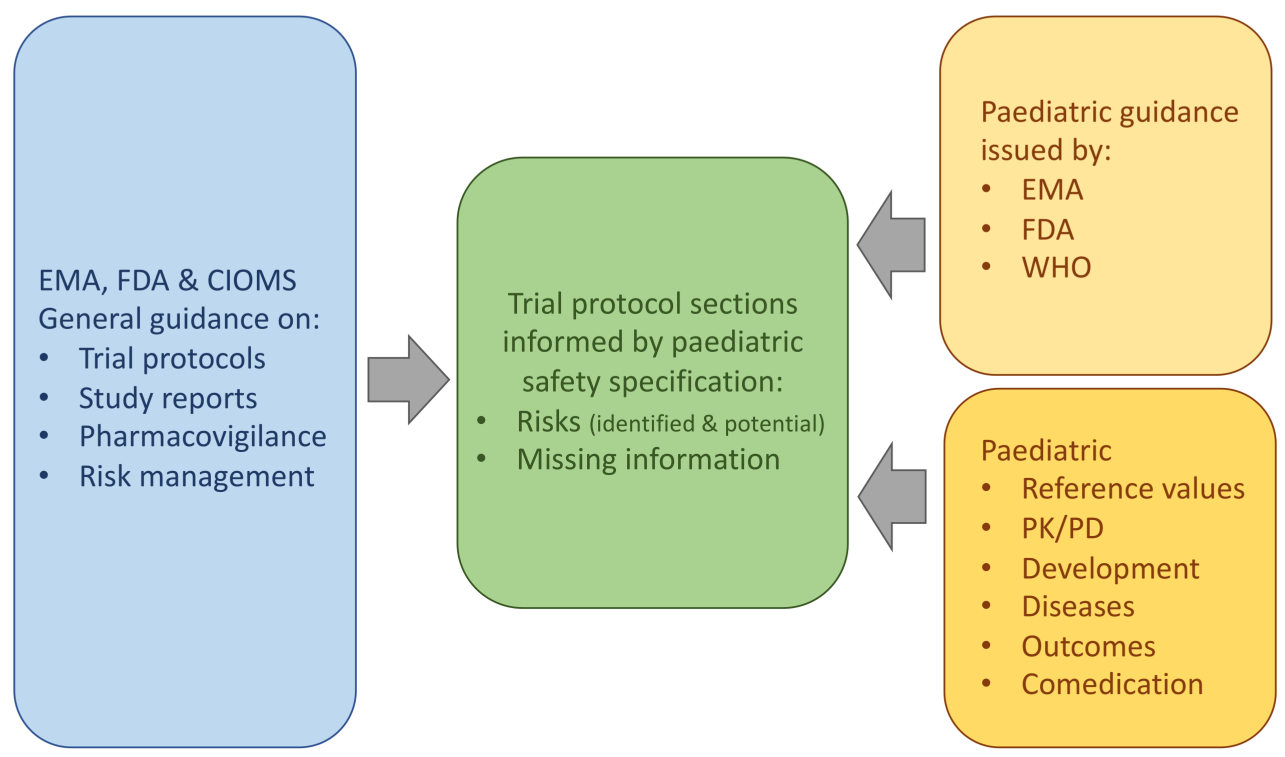

Figure 1. Paediatric research protocols and safety profiling. Process of combining information from health authorities, learned societies and the paediatric population. EMA-European Medicines Agency; FDA-Food and Drug Administration; CIOMS-Council for International Organizations of Medical Sciences; WHO_-World Health Organization; PK—Pharmacokinetic; PD— Pharmacodynamic.

General and population specific guidance documents were combined to illustrate how the safety data of the study drug and the specifics of the paediatric study population can be used to develop a paediatric safety specification (Figure 2) [4-6,10-12,19-28]. 


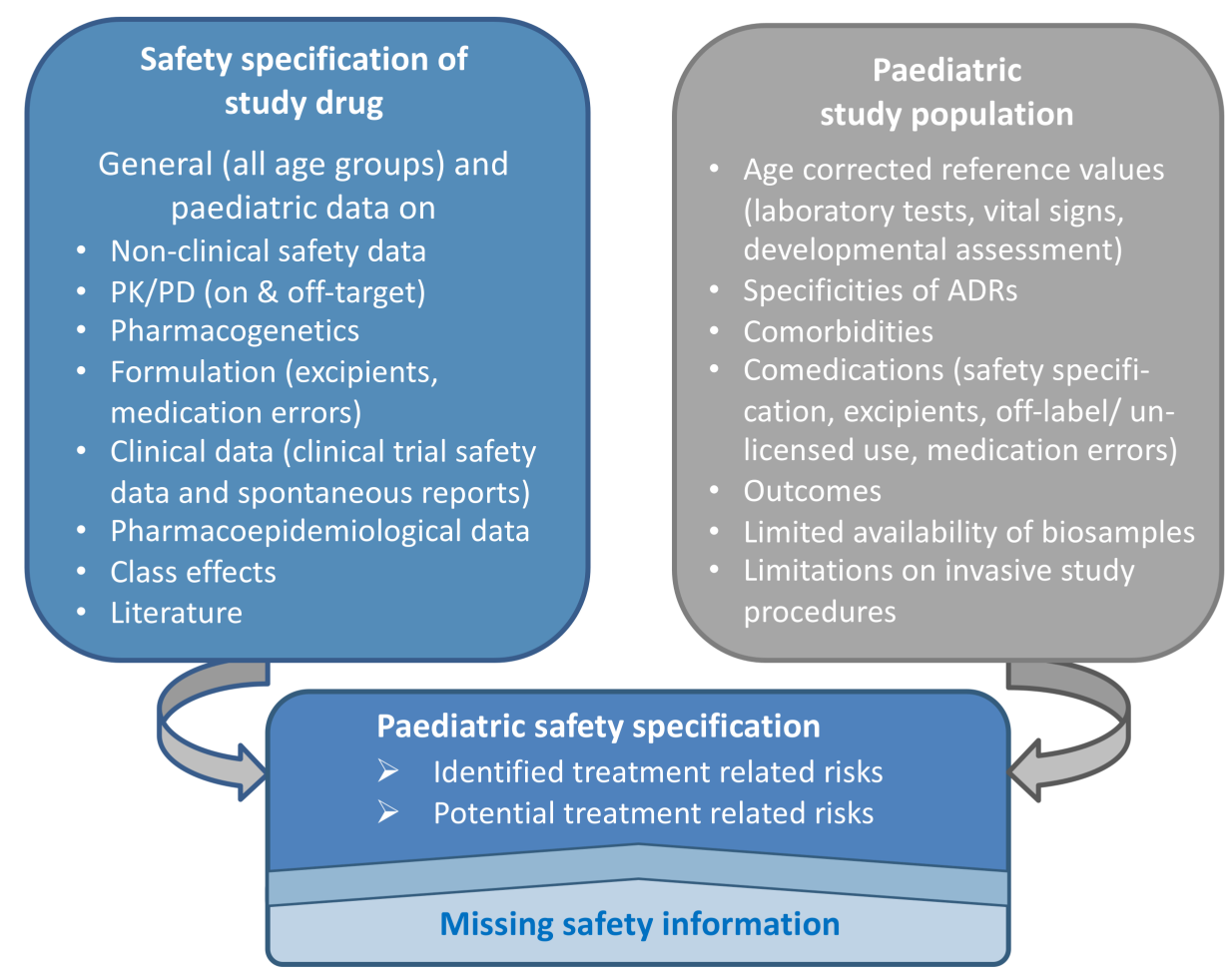

Figure 2. Data informing the paediatric safety specification. ADR—Adverse drug reaction; PKPharmacokinetic; PD-Pharmacodynamic.

Based on existing general and paediatric guidance documents, issued notably by CIOMS, the EMA and FDA, a figure was developed showing how the paediatric safety specification informs risk management and pharmacovigilance in a paediatric protocol (Figure 3) [4-6,10,12,23,24,26,28].

Since information on child specific challenges for the development of a paediatric safety specification are scattered in a considerable number of, mainly regulatory documents, a checklist was developed summarising points to consider for developing a paediatric safety specification (Table 1) [4-6,10-12,19-28].

Many regulatory guidance documents provided cross-references to related guidelines. Thus, a figure was developed to illustrate this interrelatedness for paediatric drug safety research. It shows how the paediatric safety specification, pharmacovigilance, risk management, paediatric trials, and clinical practice form part of a continuous cycle improving the understanding and management of the treatment related risks in children (Figure 4) [4-6,10,12,23,24,27,28].

Finally, the sections relating to drug safety in the EMA's ICH E6 protocol guidance were reviewed [11]. Points to consider for the development of the safety sections of paediatric protocols were added. Examples of published paediatric studies were included to illustrate how the ICH E6 guidance can be translated into paediatric protocols (Table 2). 
Table 1. Proposal for a checklist for the development of a paediatric safety specification (not exhaustive).

\begin{tabular}{|c|c|c|c|c|c|}
\hline \multirow{2}{*}{\multicolumn{2}{|c|}{ Points to Consider for the Development of a Paediatric Safety Specification }} & \multicolumn{4}{|c|}{ Data Available for * } \\
\hline & & \multirow[t]{2}{*}{ Adults } & \multirow[t]{2}{*}{$\begin{array}{l}\text { Children But Not Age } \\
\text { Group of Study } \\
\text { Population }\end{array}$} & \multirow[t]{2}{*}{$\begin{array}{l}\text { Age Group of } \\
\text { Paediatric Study } \\
\text { Population }\end{array}$} & \multirow[t]{2}{*}{$\begin{array}{l}\text { No } \\
\text { Data }\end{array}$} \\
\hline Is there safety data on the stu & rug? ${ }^{+}$ & & & & \\
\hline Nonclinical safety & Consider assessment of developmental toxicity $[20,21]$ & & & & \\
\hline $\begin{array}{c}\text { Pharmaco- } \\
\text { kinetics (PK) }\end{array}$ & $\begin{array}{l}\text { If there is insufficient paediatric data, consider doing a PK study prior to an } \\
\text { efficacy/safety study }[22,23,29]\end{array}$ & & & & \\
\hline $\begin{array}{c}\text { Pharmaco- } \\
\text { dynamics (PD) }\end{array}$ & $\begin{array}{l}\text { Consider the feasibility of a paediatric PD study (on \& off- } \\
\text { target) prior to an efficacy/safety study and/or include PD into the study protocol } \\
{[22,24,29]}\end{array}$ & & & & \\
\hline $\begin{array}{l}\text { Pharmaco- } \\
\text { genetics }\end{array}$ & Consider potential effect of age group specific pharmaco-genetics [25] & & & & \\
\hline Formulation & $\begin{array}{l}\text { Ensure the formulation is adapted to the paediatric study } \\
\text { population }[24,26]\end{array}$ & & & & \\
\hline Excipients & $\begin{array}{l}\text { Consider formulation without excipients; assess potential } \\
\text { excipient toxicity and total daily excipient dose (study drug(s) and comedications } \\
{[24,26,30]}\end{array}$ & & & & \\
\hline $\begin{array}{l}\text { Medication } \\
\text { errors }\end{array}$ & Consider assessing risk for medication errors (study drug(s) and comedications) [5] & & & & \\
\hline Clinical trial safety data & $\begin{array}{l}\text { Assess cumulative clinical trial safety data for all age groups and stratified by age } \\
\text { group }[4-6,10,12,27]\end{array}$ & & & & \\
\hline Spontaneous reports & $\begin{array}{l}\text { Summarise cumulative spontaneous reports for all age groups and stratified by age } \\
\text { group }[4-6,10,12,27]\end{array}$ & & & & \\
\hline $\begin{array}{l}\text { Pharmaco- } \\
\text { epidemiolo-gical data }\end{array}$ & $\begin{array}{l}\text { Explore whether paediatric drug utilisation and safety data are available for the study } \\
\text { drug. Be aware of the specific } \\
\text { challenges for paediatric pharmacoepidemiological data [31-39] }\end{array}$ & & & & \\
\hline Class effects & Review class effects in overall population and stratified by age group $[4-6,10,12,27]$ & & & & \\
\hline Literature search & $\begin{array}{l}\text { Search for safety concerns (i.e., signals) for the study drug/drug class for all age } \\
\text { groups and children; review health authority websites }[4-6,10]\end{array}$ & & & & \\
\hline
\end{tabular}


Table 1. Cont.

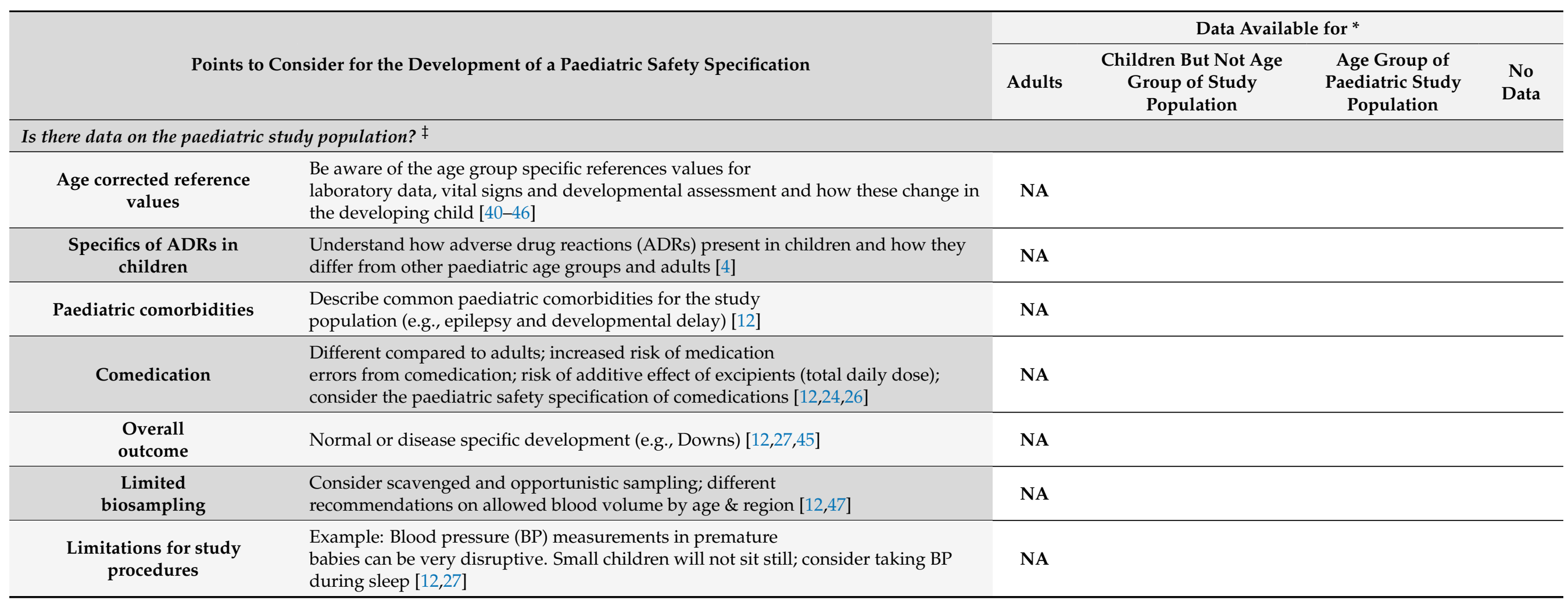

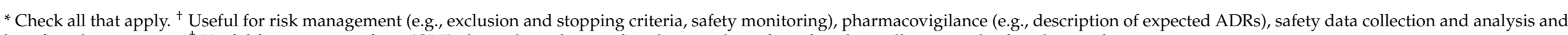
benefit-risk assessment. ${ }^{\ddagger}$ Useful for case report form (CRF) alert values, design of study procedures for safety data collection and safety data analyses. 
Table 2. EMA ICH E6 Protocol Guidance: Examples of the paediatric safety specification informing paediatric protocol development.

\begin{tabular}{|c|c|c|c|}
\hline \multicolumn{2}{|c|}{ EMA ICH E 6 Protocol Guidance [11] } & \multirow{2}{*}{$\begin{array}{l}\text { Points to Consider for the Development of Safety Sections in a } \\
\text { Paediatric Protocol }\end{array}$} & \multirow{2}{*}{ Practical Examples in the Literature } \\
\hline Protocol Sections Concerning Drug Safety & ICH Guidance & & \\
\hline \multirow{5}{*}{ Background information } & $\begin{array}{l}\text { Summary of nonclinical studies that potentially } \\
\text { have clinical significance and from clinical trials } \\
\text { relevant to the trial }\end{array}$ & $\begin{array}{l}\text { Including nonclinical safety data on excipients and missing, } \\
\text { non-clinical information (e.g., juvenile animal studies) } \\
{[4,5,20,21,30,48]}\end{array}$ & {$[48,49]$} \\
\hline & $\begin{array}{l}\text { Summary of the known and potential risks and } \\
\text { benefits }\end{array}$ & $\begin{array}{l}\text { Including risks of excipients and missing safety data (incl. } \\
\text { medication errors) }[4,5,22,24,26,30,48]\end{array}$ & [50-52] \\
\hline & $\begin{array}{c}\text { Description and justification for route of } \\
\text { administration, dosage, dosage regimen, and } \\
\text { treatment period(s) }\end{array}$ & $\begin{array}{l}\text { Age group specific PK/PD data for study drug and excipient; } \\
\text { formulation adapted to paediatric target population } \\
{[12,22-24,26,27,30,48,53]}\end{array}$ & {$[48,54,55]$} \\
\hline & Description of the population to be studied & $\begin{array}{l}\text { Describing how ADRs present in children (including risk factors and } \\
\text { confounders), comedications (including excipients and medication } \\
\text { errors) and paediatric reference ranges (laboratory tests, vital signs, } \\
\text { development) }[4-7,28]\end{array}$ & [54-59] \\
\hline & $\begin{array}{c}\text { Literature and data relevant to the trial providing } \\
\text { background for the trial }\end{array}$ & Including class effects in children [4-7] & {$[50,58,60,61]$} \\
\hline Objectives and purpose & $\begin{array}{l}\text { A detailed description of the objectives and the } \\
\text { purpose of the trial }\end{array}$ & $\begin{array}{l}\text { Safety should be a study objective (paediatric safety data is often } \\
\text { lacking and reporting SAEs is mandatory) }[4-7,19,28]\end{array}$ & {$[49,54,55]$} \\
\hline Trial design & $\begin{array}{l}\text { A description of the stopping rules or } \\
\text { discontinuation criteria for individual subjects, } \\
\text { parts of trial and entire trial }\end{array}$ & $\begin{array}{l}\text { - } \quad \text { Based on paediatric safety specification }[4,7,10,11] \\
\text { Rules based on paediatric reference ranges (laboratory tests, } \\
\text { vital signs, development) }[4,7,10,28]\end{array}$ & {$[56,62]$} \\
\hline \multirow{2}{*}{ Selection and withdrawal of subjects } & Subject exclusion criteria & $\begin{array}{l}\text { - } \quad \text { Based on paediatric safety specification }[4,7,10,11] \\
\text { - } \quad \text { Rules based on paediatric reference ranges (laboratory tests, } \\
\text { vital signs, development) }[4,7,10,28]\end{array}$ & {$[51,55,57,58,60]$} \\
\hline & $\begin{array}{l}\text { Withdrawal criteria and procedures specifying } \\
\text { when and how to withdraw subjects, type and } \\
\text { timing of data collection and FU }\end{array}$ & $\begin{array}{l}\text { - } \quad \text { Based on the paediatric safety specification }[4,7,10,11] \\
\text { Rules based on paediatric reference ranges (laboratory tests, } \\
\text { vital signs, development) }[4,7,10,28]\end{array}$ & {$[55,56,60]$} \\
\hline
\end{tabular}


Table 2. Cont.

\begin{tabular}{|c|c|c|c|}
\hline \multicolumn{2}{|c|}{ EMA ICH E 6 Protocol Guidance [11] } & \multirow{2}{*}{$\begin{array}{l}\text { Points to Consider for the Development of Safety Sections in a } \\
\text { Paediatric Protocol }\end{array}$} & \multirow{2}{*}{ Practical Examples in the Literature } \\
\hline Protocol Sections Concerning Drug Safety & ICH Guidance & & \\
\hline \multirow[b]{2}{*}{ Treatment of subjects } & FU period(s) for subjects & Safety FU: based on paediatric safety specification $[4,7,10,11]$ & [60] \\
\hline & $\begin{array}{l}\text { Treatment(s) not permitted for safety reasons } \\
\text { before/during the trial }\end{array}$ & Based on paediatric safety specification $[4,7,10,11]$ & [54] \\
\hline \multirow{4}{*}{ Assessment of safety } & Specification of safety parameters & $\begin{array}{l}\text { - } \quad \text { Based on paediatric safety specification }[4,7,10,11] \\
\text { - Parameters based on paediatric reference ranges (laboratory } \\
\text { tests, vital signs, development) }[4,7,10,28]\end{array}$ & {$[55,59,60]$} \\
\hline & $\begin{array}{l}\text { The methods and timing for assessing, recording, } \\
\text { and analysing safety parameters }\end{array}$ & $\begin{array}{l}\text { - Based on the paediatric safety specification, including } \\
\text { collection of missing paediatric safety information }[4,7,10,11] \text {; } \\
\text { may be restricted by limitations for biosampling and invasive } \\
\text { testing; physical examinations need to be adapted to children } \\
{[4,12,19,23,27,63]} \\
\text { - } \quad \text { Record medication errors for the study drug and } \\
\text { comedications in the CRF }[4,12,19,23,27] \\
\text { Record comedications in the CRF using paediatric standards } \\
\text { (i.e., } \mathrm{mg} / \mathrm{kg})[4,7,10,12] \\
\text { Adapt safety data analyses to the paediatric age group; certain } \\
\text { data analyses should only be done by paediatric specialists } \\
\text { (e.g., ECGs) }[4,7,10,11]\end{array}$ & {$[50,56,58,59,61]$} \\
\hline & $\begin{array}{l}\text { Procedures for eliciting reports and for recording } \\
\text { and reporting AEs }\end{array}$ & How do AEs/ADRs present in children, comorbidities $[4,7,10,12]$ & [54] \\
\hline & Type and duration of FU after AEs & $\begin{array}{l}\text { Based on paediatric safety specification, including missing } \\
\text { information }[4,5,7,10,11]\end{array}$ & [60] \\
\hline \multirow[t]{2}{*}{ Statistics } & $\begin{array}{c}\text { Statistical methods (including timing of interim } \\
\text { analyses) }\end{array}$ & $\begin{array}{l}\text { Based on paediatric safety specification, including missing safety } \\
\text { information }[4,5,7,10,11]\end{array}$ & {$[55,56,64]$} \\
\hline & Safety criteria for trial termination & Based on paediatric safety specification $[4,7,10,11]$ & {$[55,56]$} \\
\hline
\end{tabular}

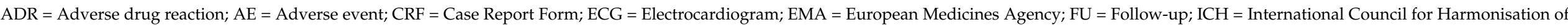
Technical Requirements for Pharmaceuticals for Human Use; PD = Pharmacodynamic; PK = Pharmacokinetic; SAE = Serious Adverse Event. 


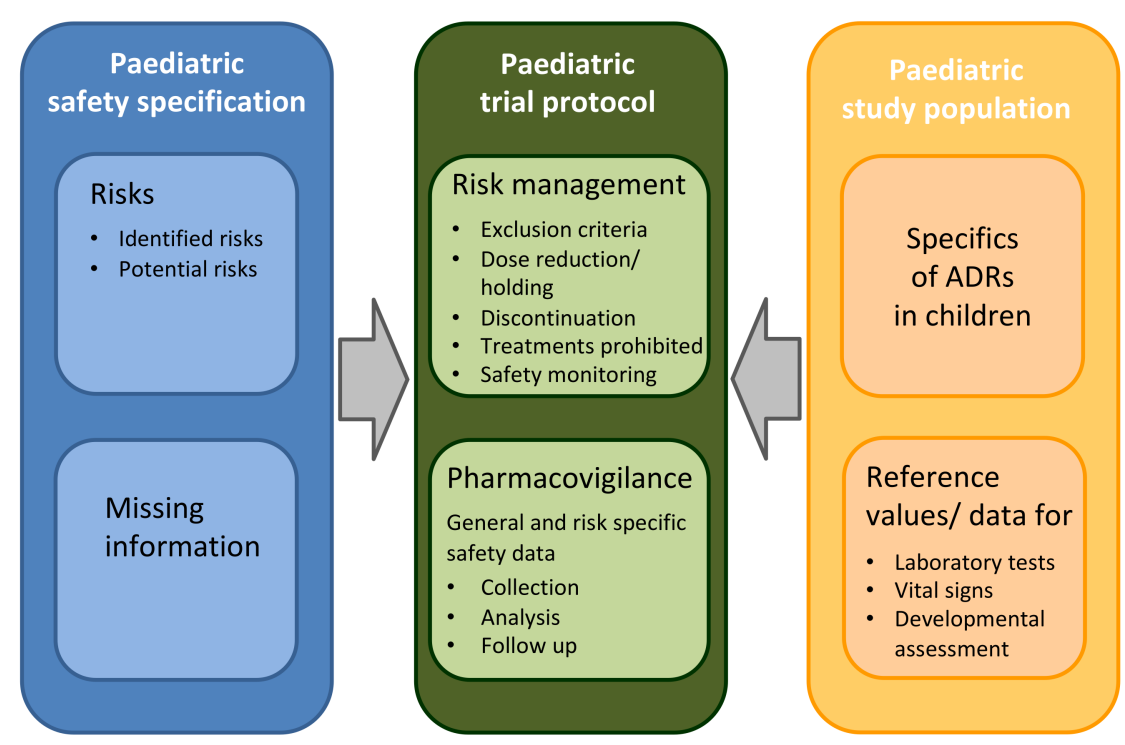

Figure 3. Relationship between paediatric safety specification and protocol development. ADRAdverse drug reaction.

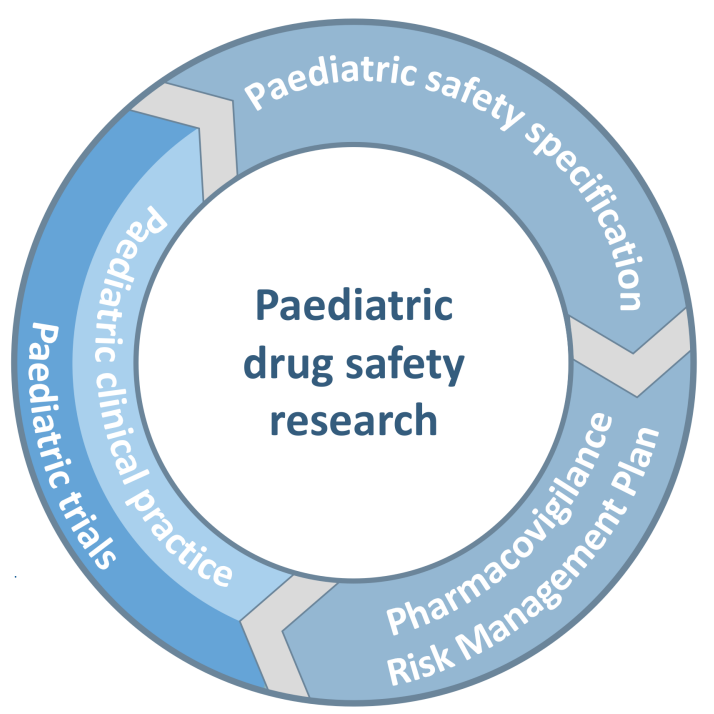

Figure 4. Paediatric drug safety research-Interaction between the paediatric safety specification, pharmacovigilance, risk management plan, clinical studies, and clinical practice.

\section{Discussion}

The conduct of clinical trials is framed by regulatory guidelines which are mainly based on recommendations by international experts and concern mostly research in adults [65]. However, these guidelines are written for pharmaceutical companies and are usually not indexed in PubMed, Embase or Web of Science [11].

Whilst all clinical research needs to be conducted according to regulatory guidelines such as Good Clinical Practice (GCP), some of the regulations applying to drug development in pharmaceutical industry may not apply to independent academic research. For example, academic researchers do not need to submit a clinical study report to regulatory authorities. However, the underlying ethical and scientific reasonsing of many regulations are relevant for all researchers because they essentially go back to the notion of protecting study subjects and informing medical practice $[7,11,63,66]$. Thus, many apply to any clinical study in children regardless of sponsorship (i.e., pharmaceutical industry, academic institutions, or research consortia) $[10-12,19-26,29,63,66]$. 
The complexity of these regulations, lack of indexing, combined with limited practical guidance for protocol development from a paediatric drug safety perspective are challenging for paediatric researchers [19]. This article intends to provide a bridge between regulatory guidelines and the practical aspects of developing evidence-based paediatric protocol sections concerning drug safety. Therefore, guidelines from regulatory and learned society publications were combined with the specifics of the paediatric population $[4-6,10,12]$.

Many drugs studied in children may have already been investigated in adults and sometimes in certain paediatric subpopulations [12]. Therefore, data will be available on nonclinical and clinical safety. It is however important to acknowledge that the interpretation of nonclinical studies for a paediatric population can be challenging [20,21]. Similarly, adult data or data from other paediatric subpopulations (e.g., other paediatric age groups), can only be used as a guide to focus safety data collection and analysis. It is recognised that adverse drug reactions (ADRs) observed in adults and other paediatric age groups may differ from those in the study population [14-17]. An ADR has been defined as a response to a drug which is noxious and unintended [67].

At the time of protocol development, the paediatric safety specification provides the necessary evidence for sections related to drug safety (Figure 3 and Table 2) such as the benefit-risk balance, exclusion criteria, rules for stopping treatment and safety monitoring [4-7,10-12]. It provides the rationale for the CRF design, management of treatment related risks, safety data collection and analysis [4-6,10]. Paediatric safety profiling takes into account the specifics of the paediatric study population, such as the epidemiology of the disease, pharmacokinetics (PK), pharmacodynamics (PD), risk factors for ADRs and adverse outcome, potential developmental toxicity and long-term risks, medication errors, comorbidities and comedications [4-6,12]. Information on pharmacogenomic risk factors and their distribution in different ethnicities can be helpful in assessing if and how these may change throughout childhood and whether genetic testing may need to be implemented at the time of trial inclusion $[23,25,68]$. Advanced techniques such as modelling and simulation, systems biology, machine learning and mathematical modelling can be used to study potential on/off target ADRs in children [12,69]. Frequent challenges for paediatric trials include the lack of age group specific PK/PD data, the need to have a formulation adapted to the study population and limited information on how short and long-term outcome can be assessed.

Using a structured approach to data collection and review provides clarity on identified and potential treatment risks and which safety information is missing (Figure 2 and Table 1). This will help deciding which safety data should be collected. Paediatric trials are a unique opportunity for high-quality safety data collection which should not be missed.

The paediatric safety specification also informs the risk management plan (RMP), which in turn provides a systematic, evidence-based approach to risk management and pharmacovigilance in paediatric clinical trials, observational studies and clinical practice [4-6,10]. RMPs are mandatory documents for pharmaceutical companies applying for a marketing authorisation in the European Union [5]. They include all safety relevant information and have a specific section for children [4,5]. The RMP also includes a plan on how missing safety information will be collected and the assessment of the effectiveness of risk management activities $[4,5]$. Similar to the safety specification, the RMP is a living document $[5,6,10]$. It is modified with each update of the safety specification. Thus, with the results of each new paediatric study, the paediatric safety specification may be updated, which in turn may be followed by an update of the RMP, the protocols of ongoing and planned paediatric studies as well as clinical practice (Figure 4).

In summary, the development of a paediatric protocol is informed by first developing a paediatric safety specification and then a risk management plan. These provide the necessary evidence for safety related protocol sections. Both are reviewed regularly and modified if needed. As new data become available, they may be updated and the sponsor will decide whether safety related protocol sections need to be amended [18]. Paediatric drug safety research is an integral part of clinical practice and paediatric research activities 
(Figure 4). It is a multidisciplinary effort that often begins prior to first-in-man studies and continues throughout the life cycle of a product $[5-7,10]$. The aim is to continue to provide children with medicines which have a favourable benefit-risk balance.

\section{Conclusions}

Paediatric drug safety in translational research is a collaborative effort of a multidisciplinary team throughout the life cycle of a medicinal product or device. Paediatric safety profiling requires an understanding of identified and potential risks as well as missing safety information in children. This informs relevant protocol sections reducing and managing treatment related risks, monitoring patients for these risks, and collecting data on frequency, severity, seriousness, and outcome of these risks. In addition, it informs plans for data collection in the CRF. Paediatric safety specification also helps to decide if any preclinical or PK studies are needed prior to conducting a trial, and which additional translational research may be warranted to improve children's health and enhance the understanding of the benefit-risk balance of the study drug in children.

Author Contributions: Conceptualisation, methodology, formal analysis, investigation, data curation, writing - original draft preparation and editing, B.A.; supervision, writing-review, supervision, project administration, funding acquisition, resources, E.J.-A. All authors have read and agreed to the published version of the manuscript.

Funding: This research was funded by the European Paediatric Translational Research Infrastructure (ID-EPTRI) project (grant agreement number 777554), funded with in H2020-INFRADEV-2017-1 program.

Acknowledgments: We thank the coordinator of EPTRI, Donato Bonifazi, and his team for the organisational support provided.

Conflicts of Interest: Both authors consider themselves to not have any competing interests for this review. B.A. has worked for GlaxoSmithKline between October 2006 and September 2009 and holds company shares. Between October 2009 and May 2015, she worked for Novartis.

Appendix A

Table A1. Search strategy.

\begin{tabular}{|c|c|}
\hline $\begin{array}{c}\text { Database; } \\
\text { Date of Last Search }\end{array}$ & Keyword/Mesh Terms/Website \\
\hline \multirow{4}{*}{$\begin{array}{c}\text { Pubmed } \\
3 \text { February } 2021\end{array}$} & 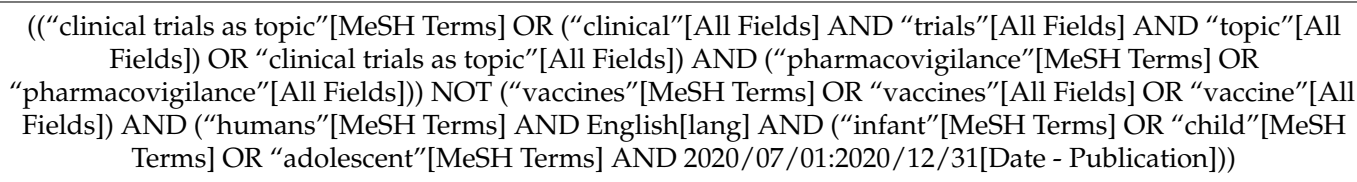 \\
\hline & $\begin{array}{l}\text { ((protocol[All Fields] AND design[All Fields]) AND ("pharmacovigilance"[MeSH Terms] OR } \\
\text { "pharmacovigilance"[All Fields])) NOT ("vaccines"[MeSH Terms] OR "vaccines"[All Fields] OR "vaccine"[All } \\
\text { Fields]) AND ("humans"[MeSH Terms] AND English[lang] AND ("infant"[MeSH Terms] OR "child"[MeSH } \\
\text { Terms] OR “adolescent"[)MeSH Terms] AND 2020/07/01:2020/12/31[Date-Publication])) }\end{array}$ \\
\hline & $\begin{array}{l}\text { ((protocol[All Fields] AND ("growth and development"[Subheading] OR ("growth"[All Fields] AND } \\
\text { "development"[All Fields]) OR "growth and development"[All Fields] OR "development"[All Fields])) AND } \\
\text { ("pharmacovigilance"[MeSH Terms] OR "pharmacovigilance"[All Fields])) NOT ("vaccines"[MeSH Terms] OR } \\
\text { "vaccines"[All Fields] OR "vaccine"[All Fields]) AND ("humans"[MeSH Terms] AND English[lang] AND } \\
\text { ("infant"[MeSH Terms] OR “child"[MeSH Terms] OR "adolescent"[MeSH Terms] AND } \\
\text { 2020/07/01:2020/12/31[Date-Publication])) }\end{array}$ \\
\hline & $\begin{array}{l}\text { (("clinical trial protocol"[Publication Type] OR "clinical trial protocols as topic"[MeSH Terms] OR "clinical trial } \\
\text { protocol"[All Fields]) AND ("pharmacovigilance"[MeSH Terms] OR "pharmacovigilance"[All Fields])) NOT } \\
\text { ("vaccines"[MeSH Terms] OR "vaccines"[All Fields] OR “vaccine"[All Fields]) AND ("humans"[MeSH Terms] } \\
\text { AND English[lang] AND ("infant"[MeSH Terms] OR “child"[MeSH Terms] OR “adolescent"[MeSH Terms] } \\
\text { AND 2020/07/01:2020/12/31[Date-Publication])) }\end{array}$ \\
\hline
\end{tabular}


Table A1. Cont.

\begin{tabular}{|c|c|}
\hline $\begin{array}{l}\text { Database; } \\
\text { Date of Last Search }\end{array}$ & Keyword/Mesh Terms/Website \\
\hline \multirow{2}{*}{$\begin{array}{l}\text { Embase } \\
3 \text { February } 2021\end{array}$} & $\begin{array}{l}\text { ('clinical trial protocol' / exp OR 'clinical trial protocol') AND ('pharmacovigilance' / exp OR pharmacovigilance) } \\
\text { NOT ('vaccine' / exp OR vaccine) AND ([newborn]/lim OR [infant]/lim OR [child]/lim OR [preschool]/lim OR } \\
\text { [school]/lim OR [adolescent]/lim) AND [humans]/lim AND [english]/lim AND [<1966-2020]/py }\end{array}$ \\
\hline & $\begin{array}{c}\text { ('clinical trial' / exp OR 'clinical trial') AND ('pharmacovigilance' /exp OR pharmacovigilance) AND } \\
\text { ([newborn]/lim OR [infant]/lim OR [child]/lim OR [preschool]/lim OR [school]/lim OR [adolescent]/lim) } \\
\text { AND [humans]/lim AND [english]/lim AND [<1966-2020]/py NOT vaccine }\end{array}$ \\
\hline \multirow{2}{*}{$\begin{array}{l}\text { Web of science } \\
5 \text { February } 2021\end{array}$} & $\begin{array}{c}\text { TOPIC: (clinical trial protocol) AND TOPIC: (pharmacovigilance) AND TOPIC: (paediatric) NOT TOPIC: } \\
\text { (vaccine)Timespan: 1956-2020. Indexes: SCI-EXPANDED, SSCI, A\&HCI, CPCI-S, CPCI-SSH, BKCI-S, BKCI-SSH, } \\
\text { ESCI, CCR-EXPANDED, IC. FILTER: English }\end{array}$ \\
\hline & $\begin{array}{c}\text { TOPIC: (clinical trial) AND TOPIC: (pharmacovigilance) AND TOPIC: (paediatric) NOT TOPIC: } \\
\text { (vaccine)Timespan: 1956-2020. Indexes: SCI-EXPANDED, SSCI, A\&HCI, CPCI-S, CPCI-SSH, BKCI-S, BKCI-SSH, } \\
\text { ESCI, CCR-EXPANDED, IC. FILTER: English }\end{array}$ \\
\hline \multirow{6}{*}{$\begin{array}{l}\text { EMA } \\
8 \text { February } 2021\end{array}$} & $\begin{array}{l}\text { https:/ / ec.europa.eu/health/documents/eudralex/vol-10_en } \\
\text { - Chapter II Safety reporting } \\
\text { - Chapter V Additional documents }\end{array}$ \\
\hline & $\begin{array}{c}\text { https://www.ema.europa.eu/en/human-regulatory/research-development/scientific-guidelines/clinical- } \\
\text { efficacy-safety/clinical-efficacy-safety-general }\end{array}$ \\
\hline & $\begin{array}{c}\text { https://www.ema.europa.eu/en/human-regulatory/research-development/scientific-guidelines/clinical- } \\
\text { efficacy-safety-clinical-pharmacology-pharmacokinetics }\end{array}$ \\
\hline & $\begin{array}{c}\text { https: } \\
\text { //www.ema.europa.eu/en/human-regulatory/research-development/scientific-guidelines/ich/ich-safety }\end{array}$ \\
\hline & $\begin{array}{c}\text { https://www.ema.europa.eu/en/human-regulatory/research-development/paediatric-medicines/ } \\
\text { scientific-guidelines-paediatrics }\end{array}$ \\
\hline & $\begin{array}{c}\text { https://www.ema.europa.eu/en/human-regulatory/post-authorisation/pharmacovigilance/good- } \\
\text { pharmacovigilance-practices }\end{array}$ \\
\hline \multirow{2}{*}{$\begin{array}{c}\text { FDA } \\
8 \text { February } 2021\end{array}$} & https://www.fda.gov/science-research/science-and-research-special-topics/pediatrics \\
\hline & $\begin{array}{c}\text { https:/ / www.fda.gov/drugs/development-resources/division-pediatric-and-maternal-health-pediatric- } \\
\text { guidances }\end{array}$ \\
\hline $\begin{array}{c}\text { CIOMS } \\
3 \text { February } 2021\end{array}$ & $\begin{array}{l}\text { https:// cioms.ch/pharmacovigilance/ } \\
\text { Filters: English, not vaccine }\end{array}$ \\
\hline $\begin{array}{l}\text { WHO } \\
3 \text { February } 2021\end{array}$ & https://www.who.int/childmedicines/publications/en/ \\
\hline
\end{tabular}




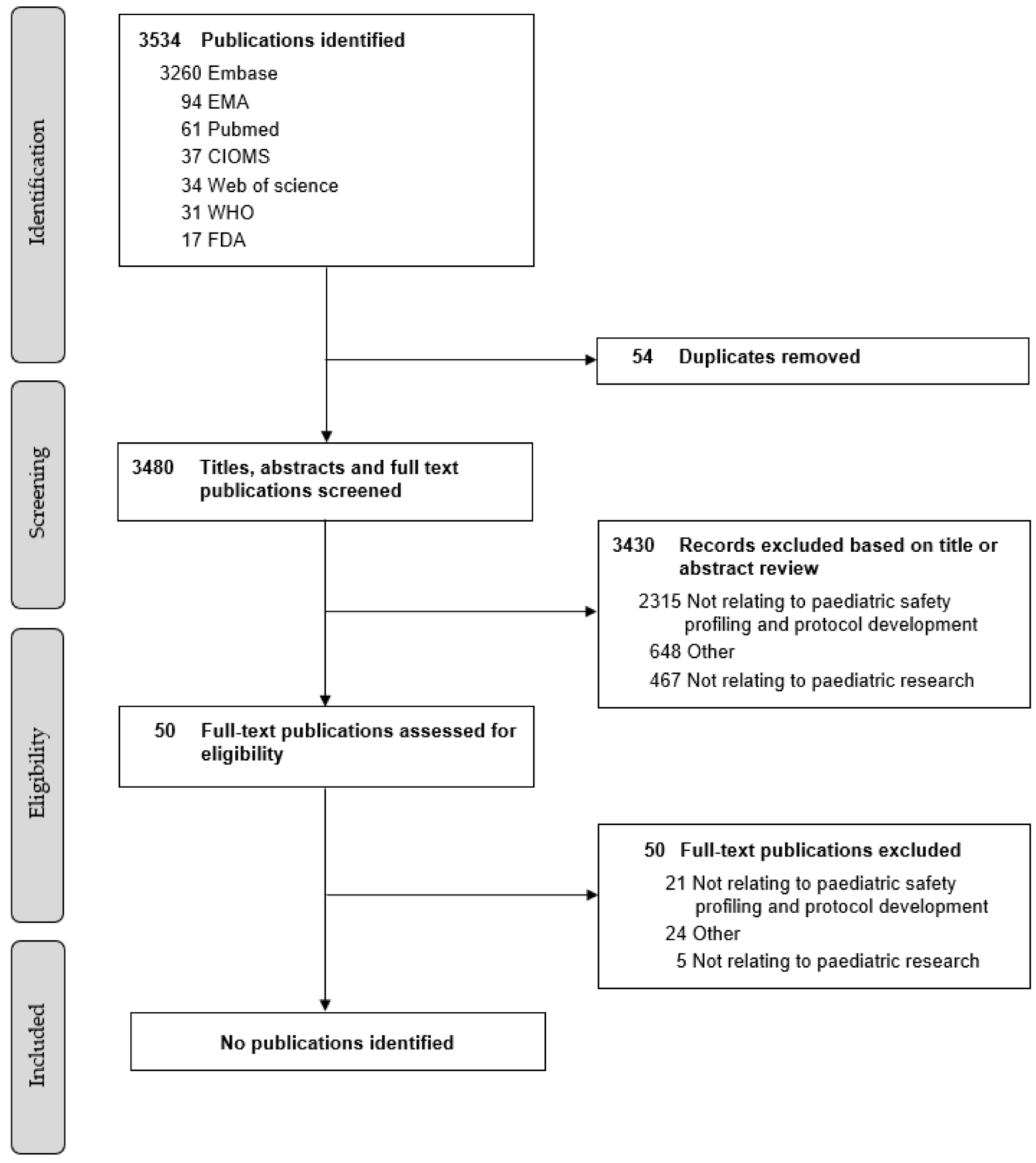

Figure A1. Paediatric safety profiling and protocol development: PRISMA Flowchart detailing selection of publications up to 31 December 2020 (last search 8 February 2021).

\section{References}

1. Rubio, D.M.; Schoenbaum, E.E.; Lee, L.S.; Schteingart, D.E.; Marantz, P.R.; Anderson, K.E.; Platt, L.D.; Baez, A.; Esposito, K. Defining Translational Research: Implications for Training. Acad. Med. 2010, 85, 470-475. [CrossRef] [PubMed]

2. Woolf, S.H. The Meaning of Translational Research and Why It Matters. JAMA 2008, 299, 211-213. [CrossRef] [PubMed]

3. Szilagyi, P.G. Translational Research and Pediatrics. Acad. Pediatr. 2009, 9, 71-80. [CrossRef] [PubMed]

4. European Medicines Agency. Guideline on Good Pharmacovigilance Practices (GVP) Product-Or Population-Specific Considerations IV: Paediatric Population; European Medicines Agency: Amsterdam, The Netherlands, $2018 . \quad$ Available online: https://www.ema.europa.eu/en/documents/scientific-guideline/guideline-good-pharmacovigilance-practices-gvpproduct-population-specific-considerations-iv_en-0.pdf (accessed on 23 January 2020). 
5. European Medicines Agency. Guidance on the Format of the Risk Management Plan (RMP) in the EU—In Integrated Format, EMA/164014/2018 Rev.2.0.1 Accompanying GVP Module V Rev.2, Human Medicines Evaluation. 31 October 2018. Available online: https: / / www.ema.europa.eu/en/documents/regulatory-procedural-guideline/guidance-format-risk-managementplan-rmp-eu-integrated-format-rev-201_en.pdf (accessed on 23 January 2020).

6. Council for International Organizations of Medical Sciences-Working Group. Management of Safety Information from Clinical Trials: Report of CIOMS Working Group VI. 2005. Available online: https:/ / cioms.ch/wp-content/uploads /2017/01/Mgment_ Safety_Info.pdf (accessed on 23 January 2020).

7. European Medicines Agency. Guidelines on Good Pharmacovigilance Practices (GVP)_Introductory Cover Note, Last Updated with Chapter P.III on Pharmacovigilance for the Use of Medicines by Pregnant and Breastfeeding Women; European Medicines Agency: Amsterdam, The Netherlands, 2019. Available online: https: / / www.ema.europa.eu/en/documents/regulatory-procedural-guideline/ guidelines-good-pharmacovigilance-practices-gvp-introductory-cover-note-last-updated-chapter-piii_en.pdf (accessed on 23 January 2020).

8. Sampson, M.R.; Benjamin, D.K.; Cohen-Wolkowiez, M. Evidence-Based Guidelines for Pediatric Clinical Trials: Focus on StaR Child Health. Expert Rev. Clin. Pharmacol. 2012, 5, 525-531. [CrossRef] [PubMed]

9. Balevic, S.J.; Cohen-Wolkowiez, M. Innovative Study Designs Optimizing Clinical Pharmacology Research in Infants and Children. J. Clin. Pharmacol. 2018, 58, S58-S72. [CrossRef]

10. European Medicines Agency; Committee for Medicinal Products for Human Use; International Council for Harmonisation of Technical Requirements for Pharmaceuticals for Human Use. ICH Topic E 2 E Pharmacovigilance Planning (Pvp)—Note for Guidance on Planning Pharmacovigilance Activities, CPMP/ICH/5716/03. 2005. Available online: https://www.ema.europa.eu/en/documents/scientific-guideline/international-conference-harmonisation-technicalrequirements-registration-pharmaceuticals-human-use_en-25.pdf (accessed on 23 January 2020).

11. European Medicines Agency; Committee for Human Medicinal Products; International Council for Harmonisation of Technical Requirements for Pharmaceuticals for Human Use. Guideline for Good Clinical Practice E6 (R2) Step 5, EMA/CHMP/ICH/135/1995. 1 December 2016. Available online: https://www.ema.europa.eu/en/documents/scientific-guideline/ich-e-6-r2-guidelinegood-clinical-practice-step-5_en.pdf (accessed on 23 January 2020).

12. European Medicines Agency (EMA), Committee for Medicinal Products for Human Use (CHMP). ICH E11(R1) Guideline on Clinical Investigation of Medicinal Products in the Pediatric Population; European Medicines Agency: Amsterdam, The Netherlands, 2017. Available online: https://www.ema.europa.eu/en/documents/scientificguideline/ich-e11r1-guideline-clinical-investigationmedicinal-products-pediatric-population-revision-1_en.pdf (accessed on 23 January 2020).

13. Beninger, P. Pharmacovigilance: An Overview. Clin. Ther. 2018, 40, 1991-2004. [CrossRef]

14. Stephenson, T. How Children's Responses to Drugs Differ from Adults. Br. J. Clin. Pharmacol. 2005, 59, 670-673. [CrossRef]

15. Rieder, M. Adverse Drug Reactions Across the Age Continuum: Epidemiology, Diagnostic Challenges, Prevention, and Treatments. J. Clin. Pharmacol. 2018, 58, S36-S47. [CrossRef]

16. Aurich-Barrera, B.; Wilton, L.; Brown, D.; Shakir, S. Paediatric Postmarketing Pharmacovigilance Using Prescription-Event Monitoring. Drug Saf. 2010, 33, 751-763. [CrossRef]

17. Aurich-Barrera, B.; Wilton, L.; Brown, D.; Shakir, S. Paediatric Post-Marketing Pharmacovigilance: Comparison of the Adverse Event Profile of Vigabatrin Prescribed to Children and Adults. Pharmacoepidemiol. Drug Saf. 2011, 20, 608-618. [CrossRef]

18. Furlan, G.; Edwards, B.; Mastroianni, A.; Koski, G. The Future of Pharmacovigilance: Proposals for More Efficient and Effective Systems-Based Approaches. Pharm. Med. 2016, 30, 137-142. [CrossRef]

19. World Health Organisation. Paediatric Clinical Trials Guidance for Assessors; World Health Organisation: Geneva, Switzerland, 2011. Available online: https:/ / www.who.int/childmedicines/CTguidance.pdf?ua=1 (accessed on 23 January 2020).

20. European Medicines Agency; Committee for Medicinal Products for Human Use; International Council for Harmonisation of Technical Requirements for Pharmaceuticals for Human Use. ICH Guideline S11 on Nonclinical Safety Testing in Support of Development of Paediatric Pharmaceuticals, Step 5, EMA/CHMP/ICH/616110/2018; European Medicines Agency: Amsterdam, The Netherlands, 31 March 2020. Available online: https://www.ema.europa.eu/en/documents/scientific-guideline/ich-guidelines11-nonclinical-safety-testing-support-development-paediatric-pharmaceuticals-step-5_en.pdf (accessed on 23 January 2020).

21. U.S Department of Health and Human Services; Food and Drug Administration; Center for Drug Evaluation and Research (CDER). Guidance for Industry Nonclinical Safety Evaluation of Pediatric Drug Products; Food and Drug Administration: Silver Spring, MD, USA, February 2006. Available online: https:/ / www.fda.gov/media/119658/download (accessed on 23 January 2020).

22. European Medicines Agency; Committee for Human Medicinal Products; International Council for Harmonisation of Technical Requirements for Pharmaceuticals for Human Use. Guideline on the Role of Pharmacokinetics in the Development of Medicinal Products in the Paediatric Population, Doc. Ref. EMEA/CHMP/EWP/147013/2004, Corrigendum; European Medicines Agency: Amsterdam, The Netherlands, 28 June 2006. Available online: https: / www.ema.europa.eu/en/documents/scientific-guideline/guidelinerole-pharmacokinetics-development-medicinal-products-paediatric-population_en.pdf (accessed on 23 January 2020).

23. U.S Department of Health and Human Services; Food and Drug Administration; Center for Drug Evaluation and Research (CDER). General Clinical Pharmacology Considerations for Pediatric Studies for Drugs and Biological Products-Guidance for IndustryDraft Guidance; Food and Drug Administration: Silver Spring, MD, USA, December 2014. Available online: https://www.fda. gov/media/90358/download (accessed on 23 January 2020). 
24. European Medicines Agency; Committee for Medicinal Products for Human Use; Quality Working Party. Guideline on Pharmaceutical Development of Medicines for Paediatric Use, EMA/CHMP/QWP/805880/2012 Rev. 2; European Medicines Agency: Amsterdam, The Netherlands, 1 August 2013. Available online: https:/ / www.ema.europa.eu/en/documents/scientific-guideline/guidelinepharmaceutical-development-medicines-paediatric-use_en.pdf (accessed on 23 January 2020).

25. European Medicines Agency, Committee for Medicinal Products for Human Use. Guideline on key Aspects for the Use of Pharmacogenomics in the Pharmacovigilance of Medicinal Products, EMA/CHMP/281371/2013; European Medicines Agency: London, UK, 24 September 2015. Available online: https:/ / www.ema.europa.eu/en/documents/scientific-guideline/guideline-key-aspects-usepharmacogenomics-pharmacovigilance-medicinal-products_en.pdf (accessed on 23 January 2020).

26. European Medicines Agency; Committee for Medicinal Products for Human Use; Paediatric Working Party. Reflection Paper: Formulation of Choice for the Paediatric Population, EMEA/CHMP/PEG/194810/2005; European Medicines Agency: Amsterdam, The Netherlands, 28 July 2006. Available online: https:/ / www.ema.europa.eu/en/documents/scientific-guideline/reflection-paperformulations-choice-paediatric-population_en.pdf (accessed on 23 January 2020).

27. European Medicines Agency; Committee for Medicinal Products for Human Use; Paediatric Committee. Guideline on the Investigation of Medicinal Products in the Term and Preterm Neonate, Doc. Ref. EMEA/536810/2008; European Medicines Agency: Amsterdam, The Netherlands, 25 June 2009. Available online: https:/ / www.ema.europa.eu/en/documents/scientific-guideline/ guideline-investigation-medicinal-products-term-preterm-neonate-first-version_en.pdf (accessed on 23 January 2020).

28. European Medicines Agency. E 3 Structure and Content of Clinical Study Reports-Note for Guidance on Structure and Content of Clinical Study Reports (CPMP/ICH/137/95), Step 5; European Medicines Agency: Amsterdam, The Netherlands, 1996. Available online: https:/ / www.ema.europa.eu/en/documents/scientific-guideline/ich-e-3-structure-content-clinical-study-reports-step5_en.pdf (accessed on 23 January 2020).

29. Kearns, G.L.; Abdel-Rahman, S.M.; Alander, S.W.; Blowey, D.L.; Leeder, J.S.; Kauffman, R.E. Developmental pharmacology-drug disposition, action, and therapy in infants and children. N. Engl. J. Med. 2003, 349, 1157-1167. [CrossRef]

30. Valeur, K.S.; Holst, H.; Allegaert, K. Excipients in Neonatal Medicinal Products: Never Prescribed, Commonly Administered. Pharm. Med. 2018, 32, 251-258. [CrossRef]

31. Lasky, T.; Artaman, A.; Czaja, A.S.; Maruti, S.S.; Osokogu, O.U.; Verhamme, K.M.; Sobel, R.E. Current needs in pediatric pharmacoepidemiology. Pharmacoepidemiol. Drug Saf. 2016, 25, 738-742. [CrossRef]

32. Lasky, T. Estimates of pediatric medication use in the United States: Current abilities and limitations. Clin. Ther. 2009, 31, 436-445. [CrossRef]

33. Neubert, A.; Sturkenboom, M.C.; Murray, M.L.; Mc Verhamme, K.; Nicolosi, A.; Giaquinto, C.; Ceci, A.; Wong, I.C. Databases for pediatric medicine research in Europe-assessment and critical appraisal. Pharmacoepidemiol. Drug Saf. 2008, 17, $1155-1167$. [CrossRef]

34. Lasky, T.; Carleton, B.; Horton, D.B.; Kelly, L.E.; Bennett, D.; Czaja, A.S.; Gifkins, D.; Osokogu, O.U.; McMahon, A.W. Real-World Evidence to Assess Medication Safety or Effectiveness in Children: Systematic Review. Drugs Real World Outcomes 2020, 7, 97-107. [CrossRef]

35. Yuan, H.; Ali, M.S.; Brouwer, E.S.; Girman, C.J.; Guo, J.J.; Lund, J.L.; Patorno, E.; Slaughter, J.L.; Wen, X.; Bennett, D.; et al. Real-World Evidence: What It Is and What It Can Tell Us According to the International Society for Pharmacoepidemiology (ISPE) Comparative Effectiveness Research (CER) Special Interest Group (SIG). Clin. Pharmacol. Ther. 2018, 104, 239-241. [CrossRef]

36. Dukanovic, J.; Osokogu, O.U.; Patel, K.; Ferrajolo, C.; Sturkenboom, M.C.; Global Research in Pediatrics Project. Comparing drug effectiveness in children: A systematic review. Pharmacoepidemiol. Drug Saf. 2018, 27, 1295-1301. [CrossRef]

37. Langan, S.M.; Schmidt, S.A.; Wing, K.; Ehrenstein, V.; Nicholls, S.G.; Filion, K.B.; Klungel, O.; Petersen, I.; Sorensen, H.T.; Dixon, W.G.; et al. The reporting of studies conducted using observational routinely collected health data statement for pharmacoepidemiology (RECORD-PE). BMJ 2018, 363, k3532. [CrossRef]

38. Osokogu, O.U.; Pacurariu, A.; Mosseveld, M.; Rijnbeek, P.; Weibel, D.; Verhamme, K.; Sturkenboom, M.C. Impact of different assumptions on estimates of childhood diseases obtained from health care data: A retrospective cohort study. Pharmacoepidemiol. Drug Saf. 2018, 27, 612-620. [CrossRef] [PubMed]

39. Baker, C.; Feinstein, J.A.; Ma, X.; Bolen, S.; Dawson, N.V.; Golchin, N.; Horace, A.; Kleinman, L.C.; Meropol, S.B.; Knight, E.M.P.; et al. Variation of the prevalence of pediatric polypharmacy: A scoping review. Pharmacoepidemiol. Drug Saf. 2019, 28, 275-287. [CrossRef] [PubMed]

40. Fernandes, M.; Villar, J.; Stein, A.; Urias, E.S.; Garza, C.; Victora, C.G.; Barros, F.C.; Bertino, E.; Purwar, M.; Carvalho, M.; et al. INTERGROWTH-21st Project international INTER-NDA standards for child development at 2 years of age: An international prospective population-based study. BMJ Open 2020, 10, e035258. [CrossRef] [PubMed]

41. O'Leary, F.; Hayen, A.; Lockie, F.; Peat, J. Defining normal ranges and centiles for heart and respiratory rates in infants and children: A cross-sectional study of patients attending an Australian tertiary hospital paediatric emergency department. Arch. Dis. Child. 2015, 100, 733-737. [CrossRef]

42. Antolini, L.; Giussani, M.; Orlando, A.; Nava, E.; Valsecchi, M.G.; Parati, G.; Genovesi, S. Nomograms to identify elevated blood pressure values and left ventricular hypertrophy in a paediatric population. J. Hypertens. 2019, 37, 1213-1222. [CrossRef]

43. Villar, J.; Papageorghiou, A.T.; Pang, R.; Salomon, L.J.; Langer, A.; Victora, C.; Purwar, M.; Chumlea, C.; Qingqing, W.; Scherjon, S.A.; et al. Monitoring human growth and development: A continuum from the womb to the classroom. Am. J. Obstet. Gynecol. 2015, 213, 494-499. [CrossRef] 
44. Tuzun, F.; Yucesoy, E.; Baysal, B.; Kumral, A.; Duman, N.; Ozkan, H. Comparison of INTERGROWTH-21 and Fenton growth standards to assess size at birth and extrauterine growth in very preterm infants. J. Matern. Neonatal Med. 2017, 31, $2252-2257$. [CrossRef]

45. Hatch-Stein, J.A.; Zemel, B.S.; Prasad, D.; Kalkwarf, H.J.; Pipan, M.; Magge, S.N.; Kelly, A. Body Composition and BMI Growth Charts in Children with Down Syndrome. Pediatrics 2016, 138, e20160541. [CrossRef]

46. Adeli, K.; Higgins, V.; Trajcevski, K.; Habeeb, N.W.-A. The Canadian laboratory initiative on pediatric reference intervals: A CALIPER white paper. Crit. Rev. Clin. Lab. Sci. 2017, 54, 358-413. [CrossRef]

47. Howie, S.R.C. Blood sample volumes in child health research: Review of safe limits. Bull. World Health Organ. 2010, 89, 46-53. [CrossRef]

48. Turner, M.; Duncan, J.; Shah, U.; Metsvaht, T.; Varendi, H.; Nellis, G.; Lutsar, I.; Yakkundi, S.; McElnay, J.; Pandya, H.; et al. Risk assessment of neonatal excipient exposure: Lessons from food safety and other areas. Adv. Drug Deliv. Rev. 2014, 73, 89-101. [CrossRef]

49. Devroe, S.; Lemiere, J.; Van De Velde, M.; Gewillig, M.; Boshoff, D.; Rex, S. Safety and feasibility of xenon as an adjuvant to sevoflurane anaesthesia in children undergoing interventional or diagnostic cardiac catheterization: Study protocol for a randomised controlled trial. Trials 2015, 16, 74. [CrossRef]

50. Lyttle, M.D.; Paediatric Emergency Research in the United Kingdom \& Ireland (PERUKI); Gamble, C.; Messahel, S.; Hickey, H.; Iyer, A.; Woolfall, K.; Humphreys, A.; Bacon, N.E.A.; Roper, L.; et al. Emergency treatment with levetiracetam or phenytoin in status epilepticus in children-the EcLiPSE study: Study protocol for a randomised controlled trial. Trials 2017, 18, 283. [CrossRef]

51. Ramanan, A.V.; Dick, A.D.; Benton, D.; Compeyrot-Lacassagne, S.; Dawoud, D.; Hardwick, B.; Hickey, H.; Hughes, D.; Jones, A.; Woo, P.; et al. A randomised controlled trial of the clinical effectiveness, safety and cost-effectiveness of adalimumab in combination with methotrexate for the treatment of juvenile idiopathic arthritis associated uveitis (SYCAMORE Trial). Trials 2014, 15, 14. [CrossRef]

52. Seddon, J.A.; Garcia-Prats, A.J.; Purchase, S.E.; Osman, M.; Demers, A.-M.; Hoddinott, G.; Crook, A.M.; Owen-Powell, E.; Thomason, M.J.; Turkova, A.; et al. Levofloxacin versus placebo for the prevention of tuberculosis disease in child contacts of multidrug-resistant tuberculosis: Study protocol for a phase III cluster randomised controlled trial (TB-CHAMP). Trials 2018, 19, 693. [CrossRef]

53. Barker, C.I.S.; Standing, J.F.; E Kelly, L.; Faught, L.H.; Needham, A.C.; Rieder, M.J.; De Wildt, S.N.; Offringa, M. Pharmacokinetic studies in children: Recommendations for practice and research. Arch. Dis. Child. 2018, 103, 695-702. [CrossRef]

54. Chabala, C.; Shine Trial on behalf of the SHINE trial team; Turkova, A.; Thomason, M.J.; Wobudeya, E.; Hissar, S.; Mave, V.; Van Der Zalm, M.; Palmer, M.; Kapasa, M.; et al. Shorter treatment for minimal tuberculosis (TB) in children (SHINE): A study protocol for a randomised controlled trial. Trials 2018, 19, 237. [CrossRef]

55. Zeilmaker-Roest, G.A.; Van Rosmalen, J.; Van Dijk, M.; Koomen, E.; Jansen, N.J.G.; Kneyber, M.C.J.; Maebe, S.; Berghe, G.V.D.; Vlasselaers, D.; Bogers, A.J.J.C.; et al. Intravenous morphine versus intravenous paracetamol after cardiac surgery in neonates and infants: A study protocol for a randomized controlled trial. Trials 2018, 19, 318. [CrossRef]

56. Silcocks, P.; Whitham, D.; Whitehouse, W.P. P3MC: A double blind parallel group randomised placebo controlled trial of Propranolol and Pizotifen in preventing migraine in children. Trials 2010, 11, 71. [CrossRef]

57. Gwee, A.; Cranswick, N.; Donath, S.M.; Hunt, R.; Curtis, N. Protocol for a randomised controlled trial of continuous infusions of vancomycin to improve the attainment of target vancomycin levels in young infants: The VANC trial. BMJ Open 2018, 8, e022603. [CrossRef]

58. Waldron, C.-A.; Thomas-Jones, E.; Cannings-John, R.; Hood, K.; Powell, C.; Roberts, A.; Tomkinson, A.; Fitzsimmons, D.; Gal, M.; Harris, D.; et al. Oral steroids for the resolution of otitis media with effusion (OME) in children (OSTRICH): Study protocol for a randomised controlled trial. Trials 2016, 17, 1-10. [CrossRef] [PubMed]

59. A Webb, N.J.; Frew, E.; A Brettell, E.; Milford, D.V.; Bockenhauer, D.; A Saleem, M.; Christian, M.; Hall, A.S.; Koziell, A.; Maxwell, H.; et al. Short course daily prednisolone therapy during an upper respiratory tract infection in children with relapsing steroid-sensitive nephrotic syndrome (PREDNOS 2): Protocol for a randomised controlled trial. Trials 2014, 15, 147. [CrossRef] [PubMed]

60. Nagy, S.; Hafner, P.; Schmidt, S.; Rubino-Nacht, D.; Schädelin, S.; Bieri, O.; Fischer, D. Tamoxifen in Duchenne muscular dystrophy (TAMDMD): Study protocol for a multicenter, randomized, placebo-controlled, double-blind phase 3 trial. Trials 2019, 20, 1-14. [CrossRef] [PubMed]

61. Van Der Aa, M.P.; Elst, M.A.; Van Mil, E.G.; Knibbe, C.A.; Van Der Vorst, M.M. METFORMIN: An efficacy, safety and pharmacokinetic study on the short-term and long-term use in obese children and adolescents-Study protocol of a randomized controlled study. Trials 2014, 15, 207. [CrossRef]

62. Todd, J.; Heyderman, R.S.; Musoke, P.; Peto, T. When enough is enough: How the decision was made to stop the FEAST trial: Data and safety monitoring in an African trial of Fluid Expansion as Supportive Therapy (FEAST) for critically ill children. Trials 2013, 14, 85. [CrossRef]

63. World Medical Association. WMA-The World Medical Association-WMA Declaration of Ottawa on Child Health; World Medical Association: New Delhi, India, 2009. Available online: https:/ /www.wma.net/policies-post/wma-declaration-of-ottawa-onchild-health/ (accessed on 17 February 2020). 
64. Nishijima, D.K.; TIC-TOC Collaborators of the Pediatric Emergency Care Applied Research Network; VanBuren, J.; Hewes, H.A.; Myers, S.R.; Stanley, R.M.; Adelson, P.D.; Barnhard, S.E.; Bobinski, M.; Ghetti, S.; et al. Traumatic injury clinical trial evaluating tranexamic acid in children (TIC-TOC): Study protocol for a pilot randomized controlled trial. Trials 2018, 19, 1-10. [CrossRef]

65. International Council for Harmonisation of Technical Requirements for Pharmaceuticals for Human Use. ICH Official Web Site 2020. Available online: https:/ / www.ich.org/ (accessed on 16 January 2020).

66. World Medical Association. WMA-The World Medical Association-WMA Declaration of Helsinki-Ethical Principles for Medical Research Involving Human Subjects; World Medical Association: Fortaleza, Brazil, 2013. Available online: https://www.wma.net/ policies-post/wma-declaration-of-helsinki-ethical-principles-for-medical-research-involving-human-subjects/ (accessed on 12 February 2020).

67. European Medicines Agency. ICH Topic E 2 A Clinical Safety Data Management: Definitions and Standards for Expedited Reporting-Note for Guidance on Clinical Safety Data Management: Definitions and Standards for Expedited Reporting. Step 5, CHMP/ICH/377/95. June 1995. Available online: https:/ / www.ema.europa.eu/en/documents/scientific-guideline/ international-conference-harmonisation-technical-requirements-registration-pharmaceuticals-human-use_en-15.pdf (accessed on 3 May 2021).

68. Whirl-Carrillo, M.; McDonagh, E.M.; Hebert, J.M.; Gong, L.; Sangkuhl, K.; Thorn, C.F.; Altman, R.B.; E Klein, T. Pharmacogenomics Knowledge for Personalized Medicine. Clin. Pharmacol. Ther. 2012, 92, 414-417. [CrossRef]

69. Giangreco, N.P.; Elias, J.E.; Tatonetti, N.P. No population left behind: Improving paediatric drug safety using informatics and systems biology. Br. J. Clin. Pharmacol. 2020. [CrossRef] 